Article

\title{
Acute Effects of Low Dose of Caffeine Ingestion Combined with Conditioning Activity on Psychological and Physical Performances of Male and Female Taekwondo Athletes
}

\author{
Ibrahim Ouergui ${ }^{1}(\mathbb{D})$, Nourhene Mahdi ${ }^{1}\left(\mathbb{D}\right.$, Slaheddine Delleli ${ }^{2,3}$, Hamdi Messaoudi ${ }^{2,3}$, Hamdi Chtourou ${ }^{2,3} \mathbb{D}^{\mathbb{D}}$, \\ Zouheir Sahnoun ${ }^{4}$, Anissa Bouassida ${ }^{1}$, Ezdine Bouhlel ${ }^{5}$, Hadi Nobari $6,7,8,9, *,+\mathbb{D}$, Luca Paolo Ardigò ${ }^{10, *,+}$ (D) \\ and Emerson Franchini ${ }^{11,+}$ (iD
}

check for updates

Citation: Ouergui, I.; Mahdi, N.; Delleli, S.; Messaoudi, H.; Chtourou, H.; Sahnoun, Z.; Bouassida, A.; Bouhlel, E.; Nobari, H.; Ardigò, L.P.; et al. Acute Effects of Low Dose of Caffeine Ingestion Combined with Conditioning Activity on Psychological and Physical Performances of Male and Female Taekwondo Athletes. Nutrients 2022, 14, 571. https://doi.org/10.3390/ nu14030571

Academic Editor:

Mindy L. Millard-Stafford

Received: 23 December 2021

Accepted: 25 January 2022

Published: 28 January 2022

Publisher's Note: MDPI stays neutral with regard to jurisdictional claims in published maps and institutional affiliations.

Copyright: (C) 2022 by the authors. Licensee MDPI, Basel, Switzerland. This article is an open access article distributed under the terms and conditions of the Creative Commons Attribution (CC BY) license (https:// creativecommons.org/licenses/by/ $4.0 /)$.
1 High Institute of Sport and Physical Education of Kef, University of Jendouba, Kef 7100, Tunisia; ouergui.brahim@yahoo.fr (I.O.); nourhene648@gmail.com (N.M.); bouassida_anissa@yahoo.fr (A.B.)

2 High Institute of Sport and Physical Education of Sfax, University of Sfax, Sfax 3000, Tunisia; sdelleli2018@gmail.com (S.D.); hamdimessaoudihamdi@gmail.com (H.M.); h_chtourou@yahoo.fr (H.C.)

3 Activité Physique, Sport et Santé, UR18JS01, Observatoire National du Sport, Tunis 1003, Tunisia

4 Pharmacology Department, Faculty of Medicine, University of Sfax, Sfax 3000, Tunisia; zouheir.sahnoun@fmsf.rnu.tn

5 Laboratory of Cardio-Circulatory, Respiratory, Metabolic and Hormonal Adaptations to Muscular Exercise, Faculty of Medicine Ibn El Jazzar, University of Sousse, Sousse 4000, Tunisia; ezdine_sport@yahoo.fr

6 HEME Research Group, Faculty of Sport Sciences, University of Extremadura, 10003 Cáceres, Spain

7 Department of Physical Education and Sports, University of Granada, 18010 Granada, Spain

8 Department of Exercise Physiology, Faculty of Educational Sciences and Psychology, University of Mohaghegh Ardabili, Ardabil 56199-11367, Iran

9 Sports Scientist, Sepahan Football Club, Isfahan 81887-78473, Iran

10 Department of Neurosciences, Biomedicine and Movement Sciences, School of Exercise and Sport Science, University of Verona, Via Felice Casorati 43, 37131 Verona, Italy

11 Martial Arts and Combat Sports Research Group, School of Physical Education and Sport, University of São Paulo, São Paulo 05508-030, Brazil; efranchini@usp.br

* Correspondence: hadi.nobari1@gmail.com (H.N.); luca.ardigo@univr.it (L.P.A.)

+ These authors share last authorship.

\begin{abstract}
This study investigated low-dose caffeine ingestion, conditioning activity (CA) effects on psycho-physical performances in young taekwondo athletes. In a randomized, double-blind, counterbalanced, crossover design, 20 athletes (10 males; $17.5 \pm 0.7 \mathrm{yrs}$ ) performed taekwondospecific agility test (TSAT), $10 \mathrm{~s} /$ multiple frequency speed of kick test (FSKT-10s/FSKT-mult) after ingesting $3 \mathrm{mg} \cdot \mathrm{kg}^{-1}$ caffeine (CAF) or placebo (PL) $60 \mathrm{~min}$ before performing standard warm-up without $(\mathrm{NoCA})$ or with $\mathrm{CA}(3 \times 10$ vertical jumps above $40 \mathrm{~cm})$, resulting in four experimental $(\mathrm{PL}+\mathrm{NoCA}, \mathrm{CAF}+\mathrm{NoCA}, \mathrm{PL}+\mathrm{CA}$, and CAF + CA) and one control (warm-up session without CAF or CA) conditions. Mood/physical symptoms (MPSS), subjective vitality (SVS), and feeling (FS) scales were analyzed post-to-pre for all conditions. Ratings of perceived-exertion and perceivedrecovery status were determined after tests. For TSAT, CAF + CA induced better performance compared with all conditions $(p<0.001)$. For FSKT-10s and FSKT-mult, CAF + CA induced better performance compared with all conditions $(p<0.001)$. For MPSS, FS, CAF + NoCA induced higher scores than PL + NoCA and PL + CA ( $p=0.002,0.009$ for MPSS; $p=0.014,0.03$ for FS). For SVS, PL + CA elicited lower scores than PL + NoCA and CAF + NoCA $(p=0.01,0.004)$. Sex comparisons resulted in better performances for males for TSAT $(p=0.008)$, FSKT-10s $(p<0.001)$, FSKT-mult $(p<0.01)$, MPSS $(p=0.02)$, SVS $(p=0.028)$, and FS $(p=0.020)$ scores. Caffeine and conditioning activity are two efficient performance-enhancing strategies, which could synergistically result in greater psycho-physical performances.
\end{abstract}

Keywords: combat sports agility; ergogenic aid; plyometric 


\section{Introduction}

Taekwondo is a combat sport characterized by brief and intense actions interspersed by long, low-intensity movements [1]. The high-intensity actions performed during 2 min rounds require a high level of agility, quick reactions, and a high capacity to kick powerfully at a limited scoring area and under strict time constraints [2]. To prepare taekwondo athletes to handle the competition demands, coaches and sport scientists are increasingly employing different performance optimization strategies. Among the most proposed strategies in the field of athletic performance is the use of caffeine (CAF) as an ergogenic aid, which has been widely introduced to improve explosive exercise performances [3]. The ergogenic potential of CAF was attributed to both central and peripheral mechanisms $[4,5]$. In fact, CAF exerts its effect via blocking the adenosine $A_{1}$ and $A_{2 a}$ receptors, which reduces fatigue level, improves neurotransmission, and increases motor unit firing rates [5]. In the periphery, CAF enhances muscle contraction throughout calcium ion mobilization [6] and phosphodiesterase inhibition [4].

In combat sports, there is no consensus about CAF effects on physical performances [7]. In fact, some investigations reported improvements [8-11], while others did not [12,13]. This difference could be related to the methodological and the inter-individual variations. In fact, the ergogenic effects of CAF are influenced by participants' characteristics (i.e., sex, age, training status), CAF supplementation protocol (i.e., dose, form, ingestion time, time of day of CAF supply), tolerance to CAF, genetics, and nature of exercise [3,7,14-17].

While CAF alone offers an attractive and useful tool to improve physical performance, as well as physiological and psychological responses, there are other strategies used by coaches to enhance muscle performance and may be synergistic when combined with CAF [18]. In fact, the post-activation performance enhancement (PAPE), previously denominated as post-activation potentiation (PAP) in classical investigations $[19,20]$, is the stimulus by which muscular performance is enhanced in response to a voluntary conditioning activity (CA) $[19,20]$. Indeed, PAPE may occur when the potentiation effects are higher than the neuromuscular fatigue generated by the CA [19]. Since PAP and PAPE were distinguished as two different phenomena [20], PAPE has been explained by increased muscle temperature, intramuscular fluid accumulation, and increased neural drive [19]. To generate a PAPE stimulus, different modes of CA have been used [21]. However, plyometric exercises were suggested to be better than traditional resistance CAs [22]. This was reasonable as plyometric exercises may cause less fatigue than traditional resistance exercise, allowing stronger enhancement effects and shorter time to achieve it [22]. In combat sports, there were contradictory results, with some studies revealing performance enhancement following plyometric CA [23-25], whereas others did not [26,27].

To our current knowledge, only one study [18] investigated the effects of PAP, with and without prior $5 \mathrm{mg} / \mathrm{kg}$ CAF ingestion on countermovement jump performance in male soccer players and showed that performance was better in 1,3, and 5 min after the conditioning activity in CAF condition, whereas in the placebo condition, performance improved only in the 5-minute time-point. However, studies in this field of investigation combat sports, especially within taekwondo practitioners, are limited. Moreover, the large inter-individual response variation was considered as a common reason for the contradictory results among studies [18]. There are few investigations that compared performances between sexes in both CAF [28-30] and CA [31] interventions and showed that males were more responsive than females due to hormonal variation [32], menstrual cycle phases [33], the consumption of oral contraceptive which extended caffeine half-life and prolonged responses [10], difference in muscle typology (i.e., higher type II fiber in males than in females) [31], and body composition [29].

From a psychological side, CAF has been reported to enhance positive mood components (i.e., vigor and tension) and increase the subjective vitality profile [34,35], reduce fatigue, and increase the feeling of pleasure even when energy levels are low [36]. In taekwondo, like other sports, the ability to reduce fatigue and present more positive psychological responses could result in greater performances [1]. However, the effectiveness of 
low doses of CAF on these psychological aspects was not examined in taekwondo athletes, especially when it is combined with a CA. Therefore, the present study investigated the effects of using a plyometric CA combined with a low dose of caffeine ingestion on physical performances and psychological responses of young male and female taekwondo athletes. Because caffeine supplementation has been reported to reduce fatigue [4] and CA has been proposed as an efficient strategy to enhance performance $[19,20]$, it was hypothesized that the combination might cause better improvements compared with the isolated conditions. Moreover, as the impact of CA is greater in stronger subjects [22], and CAF metabolism is greater in males than in females [17], it was hypothesized that males would present better performances than females.

\section{Materials and Methods}

\subsection{Participants}

A priori power analysis was calculated using the $G^{*}$ Power software (Version 3.1.9.4, University of Kiel, Kiel, Germany) using the F test family (repeated measures, withinbetween interaction), with five conditions. The analysis revealed that a total sample size of 15 would be sufficient to find significant and large-sized effects of condition (effect size $\mathrm{f}=0.7, \alpha=0.05$ ) with an actual power of $95 \%$. Because some athletes could drop out of the study, twenty taekwondo athletes (10 males and 10 females; age: $17.5 \pm 0.7$ years; body mass: $59.2 \pm 10.0 \mathrm{~kg}$; height: $168 \pm 9 \mathrm{~cm}$ ) with at least 6 years of experience volunteered to participate in this study. All participants were non-smokers, and according to the classification proposed by Filip et al. [37], they were moderate CAF consumers (less than 3 cups of coffee per day), as one cup of coffee is assumed to contain $100 \mathrm{mg}$ of CAF [38]. None of the athletes was suffering from any restrictions to sport practice (e.g., cardiovascular diseases), they did not use dietary supplements or anti-inflammatory drugs, and they had not taken psychotropic drugs in the 3 months prior to the study. For females, they were selected as non-contraceptive pills users, as these medications may interfere with caffeine pharmacokinetics [10]. Moreover, the menstrual cycle was considered in the organization of the experimental sessions (i.e., all female athletes were instructed to participate in the testing during their early follicular phase). The participants were asked to follow the same diet, avoid alcoholic substances and vigorous exercise, and restrain from CAF consumption (in drinks and supplements) during the $48 \mathrm{~h}$ prior to each session. Before taking part in the experimentation, all participants were informed about the procedures, the possible risks, and the discomforts involved in the investigation, and they and/or their parents signed an informed consent form. This study was conducted in accordance with the Declaration of Helsinki, and the protocol was fully approved by a local research ethics committee (CPP SUD N ${ }^{\circ} 0332 / 2021$ ).

\subsection{Experimental Design}

This study followed a double-blind, counterbalanced, crossover design to investigate the effects of CAF supplementation and CA during the warm-up on the subsequent $10 \mathrm{~s}$ frequency speed of kick test (FSKT-10s), multiple frequency speed of kick test (FSKTmult), and taekwondo-specific agility test (TSAT) performances, the Mood and Physical Symptoms Scale (MPSS), the Subjective Vitality Scale (SVS), the Feeling Scale (FS), the rating of perceived exertion (RPE) and perceived recovery status (PRS).

During the first visit, familiarization about the procedures and tests was conducted, and athletes' anthropometrics characteristics were determined ( $72 \mathrm{~h}$ before the experiments). For the test sessions, athletes were submitted to five conditions (4 experimental conditions and 1 control). In fact, in a double-blind fashion, athletes ingested a $3 \mathrm{mg} / \mathrm{kg}$ of CAF or placebo (PL) diluted in $200 \mathrm{~mL}$ of water. The $3 \mathrm{mg} / \mathrm{kg}$ of caffeine was chosen as it was considered a safe dose, and its effectiveness was previously reported in combat sports [39]. One hour after supplementation, the athletes executed 2 warm-ups protocols, consisting of a standard warm-up (i.e., without CA (NoCA), 10 min running at $9 \mathrm{~km} / \mathrm{h}$ followed by 2 min rest), or warm-up session followed by a plyometric conditioning activity protocol (i.e., 
3 sets of 10 vertical jumps above $40 \mathrm{~cm}$ ). During the control session, athletes were submitted only to a standard warm-up session, in which athletes performed only 10 min of running at $9 \mathrm{~km} / \mathrm{h}$ followed by $2 \mathrm{~min}$ of rest. During conditions in which a CA was performed, $10 \mathrm{~min}$ of rest after the physical tests was attributed. This post-stimulus recovery period was chosen based on the results of a previous meta-analysis [40], which showed that 7-10 min was an optimal recovery period to maximize the effects of potentiation. Furthermore, the Physical Mood and Symptoms Scale (MPSS), the Subjective Vitality Scale (SVS), and the Feeling Scale (FS) were completed before and $1 \mathrm{~h}$ post-supplementation. The $1 \mathrm{~h}$ duration was used since it was considered as an optimal duration for full absorption of caffeine and allowing the peak concentration of caffeine to be observed [41]. Therefore, athletes performed the specific tests through five different conditions: (1) control condition (no supplementation + NoCA), (2) placebo without CA (PL + NoCA), (3) caffeine without CA $(\mathrm{CAF}+\mathrm{NoCA}),(4)$ placebo with CA $(\mathrm{PL}+\mathrm{CA})$, and (5) caffeine with CA $(\mathrm{CAF}+\mathrm{CA})$. To compare the effects of different conditions on perceived exertion and recovery, athletes were asked to rate their perceived exertion and recovery after finishing the testing procedure (Figure 1). The sessions were separated by an interval of seven days to allow sufficient recovery between sessions and to ensure caffeine elimination [41]. For each experimental session and to avoid identification, supplements were administered in opaque, unmarked containers and handled by a trained person. Participants were instructed to not discuss or compare tastes or make assumptions about what they had ingested and were supervised by staff to ensure that they drank the full amount, and no exchanges were allowed. In addition, to check the success of blinding, each subject was asked to identify what he/she took, and any of the athletes distinguished correctly which supplement had been ingested. All the sessions were conducted at the same time of day (from 10 a.m. to 12 p.m.) to overcome the time-of-day effects.

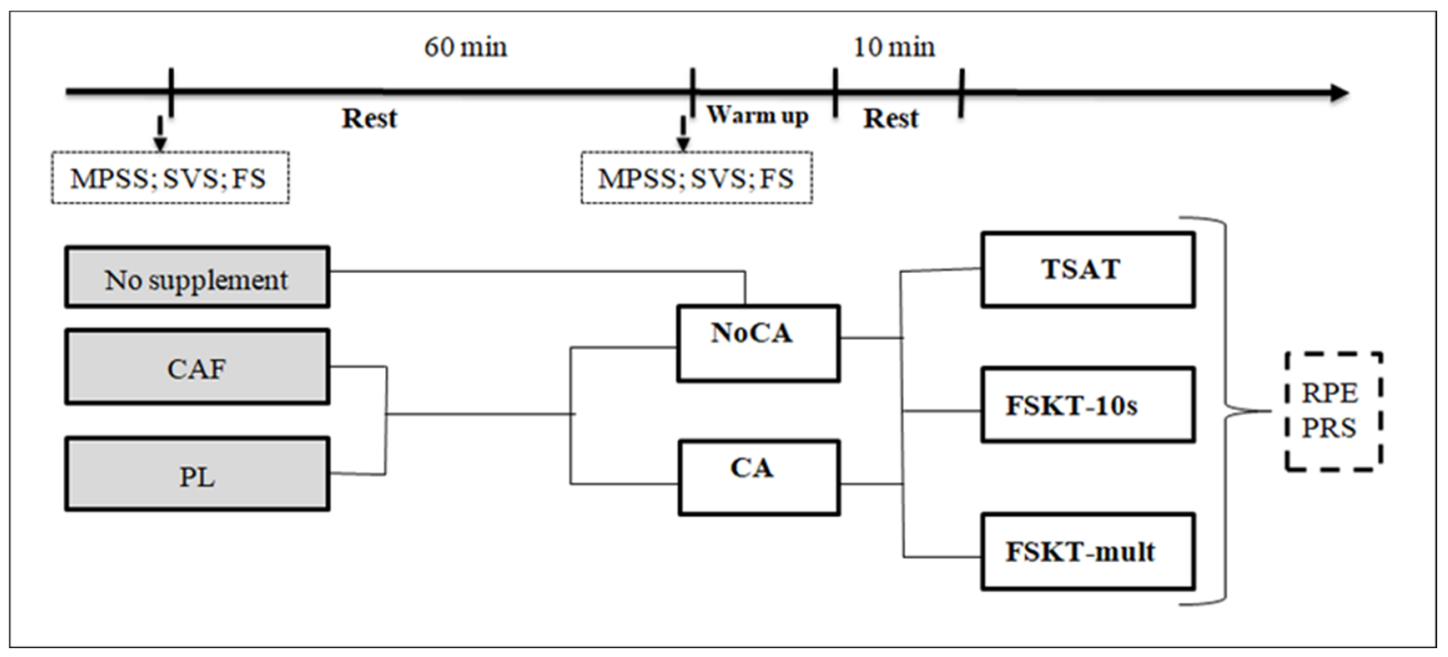

Figure 1. Schematic representation of the study design. MPSS-Mood and Physical Symptoms Scale; SVS-Subjective Vitality Scale; FS—Feeling Scale; RPE—rating of perceived exertion; PRS—perceived recovery status; $\mathrm{PL}$ - placebo; CAF—caffeine; CA—conditioning activity; TSAT—taekwondo-specific agility test; FSKT-10s-10 s frequency speed of kick test-FSKT-mult: multiple frequency speed of kick test.

\subsection{Testing Procedure}

\subsubsection{Taekwondo-Specific Agility Test}

The athlete began the test from a guard position with both feet behind the start/finish line. At his/her discretion, the athlete moved as quickly as possible towards the center point. Then, following his/her own preference, he/she turned towards partner 1 by performing a sideways movement and performed a roundhouse kick lead leg. Subsequently, he/she turned and shifted to partner 2 and performed a right another roundhouse kick with the 
other lead leg. Next, he/she returned to the center, moved forward to partner 3 in a guard position, and performed a double roundhouse kick. Finally, the athlete retreated to the start/finish line [42]. The completion time was measured using photocells (Brower Timing Systems, Salt Lake City, UT, USA). Three trials were performed by each athlete, and the best one was used for analysis. The intra-class correlation coefficient (ICC) for test-retest in the present study was 0.98 .

\subsection{2. $10 \mathrm{~s}$ Frequency Speed of Kick Test}

The test was performed as described by da Silva Santos et al. [27]. The athlete had to perform the maximum number of kicks against a punching bag by alternating the right and left leg. The technique used during the test was the Bandal Chagui. The number of techniques performed during the $10 \mathrm{~s}$ of the test represented the performance index [27]. The ICC for the test-retest in the present study was 0.95 .

\subsubsection{Multiple Frequency Speed of Kick Test}

The same procedures in the FSKT-10s were adopted for the FSKT-mult. The athlete performed five sets of FSKT-10s with a $10 \mathrm{~s}$ rest interval between repetitions. Performance was determined by the total number of kicks performed in each set and the total number of kicks in 5 sets, which allowed determining the kick decrement index (DI), which is calculated as follows [43] (Equation (1)):

DI $(\%)=[1-(($ FSKT1 + FSKT2 + FSKT3 + FSKT4 + FSKT5 $) /($ Best FSKT set $\times$ Numbers of sets $))] \times 100$

The ICC for the test-retest in the present study was 0.85 .

\subsubsection{Mood and Physical Symptoms Scale}

The questionnaire consists of 20 items answered on a scale from 1 to 5 with $1=$ strongly disagree and $5=$ strongly agree, describing feelings of mood, including alertness and various physical sensations. These 20 points were reduced to a smaller number of variables for analysis as follows: "alertness" (I feel energetic, I feel very tired, I can think clearly, I don't feel like doing much, I feel very awake, I have trouble thinking clearly, I feel like doing something active, I feel sleepy), "happy/friendly" (I feel happy, I feel friendly, sad, angry, happy), "headache" (I have a headache), and "other negative physical symptoms" (my muscles hurt, I feel strong, my stomach hurts, my fingers are tingling, I feel healthy, I feel good) [44]. The MPSS showed good reliability, with Cronbach's alpha of 0.78 [44].

\subsubsection{Subjective Vitality Scale}

A simple self-report scale designed to subjectively measure the level of vitality was used. Participants were asked to indicate their agreement with 7 statements related to subjective feelings of energy and vitality using a 7-point Likert scale, where $1=$ not at all true and $7=$ very true. The 7 items were: (1) I feel alive and vital, (2) I don't feel very energetic, (3) sometimes I feel so alive I just want to burst, (4) I have energy and spirit, (5) I look forward to each new day, (6) I nearly always feel alert and awake and (7) I feel energized. The possible range of a score was from 7 to 49 , with higher scores indicating stronger subjective vitality [45]. The SVS showed good reliability, with Cronbach's alphas of 0.84 and 0.86 for two samples [45].

\subsubsection{Feeling Scale}

The FS was used to assess general affective valence (pleasure and dissatisfaction), described by Hardy and Rejeski [46]. Participants indicated their current feelings on an 11-point bipolar scale ranging from +5 to -5 . The language anchors were very good $(+5)$, good (+3), fairly good (+1), neutral (0), fairly bad ( -1$)$, bad ( -3$)$, and very bad (-5). The FS has been shown to be related to other measures of affective valence and present and past physical activity participation [46]. 


\subsubsection{Rating of Perceived Exertion}

Perceived exertion was assessed using the $0-10$ exertion perception scale adapted by Foster et al. [47]. This is a scale ranging from 0 to 10, with corresponding verbal expressions, that gradually increases with the intensity of perceived sensation $(0=$ Nothing at all; $1=$ Very light; 2 = Light; 2-3 = Moderate; 4-5 = Somewhat heavy; 6-7 = Heavy; 8-9 = Very heavy, and $10=$ Very, very heavy).

\subsubsection{Perceived Recovery Status}

The PRS was used to assess the athlete's level of recovery. All participants complete a self-assessment report in the form of an 11-point representation scale from 0 (very little recovery/extremely tired) to 10 (very well recovered/very energetic) [48].

\subsection{Statistical Analysis}

The statistical analysis was performed using SPSS 20.0 statistical software (IBM corps., Armonk, NY, USA). Data are presented as mean and standard deviation. The KolmogorovSmirnov test was used to check and confirm the normality of data sets, and the Levene test was used to verify the homogeneity of variances. Sphericity was tested using the Mauchly test. A two-way analysis of variance (ANOVA) (condition $\times$ sex) with repeated measurements was used to compare TSAT, FSKT-10s, RPE, and RPS throughout the different experimental conditions, while the FSKT-mult outcomes (total number of techniques and decrement index) were compared using a multivariate analysis of variance. Moreover, a three-way ANOVA (condition $\times$ time $\times$ sex) was performed to compare MPSS, SVS, and FS, and partial eta squared $\left(\eta_{\mathrm{p}}{ }^{2}\right)$ effect size values were reported and classified as $0.01=$ small, $0.09=$ medium, and $0.25=$ large [49]. When the ANOVA indicated a significant difference, Bonferroni was used as a post hoc test. Due to the substantial number of results, only significant differences were reported. Standardized effect size analysis (Cohen's d) was used to interpret the magnitude of differences between variables and considered as trivial $(\leq 0.20)$, small $(\leq 0.60)$, moderate $(\leq 1.20)$, large $(\leq 2.0)$, very large $(\leq 4.0)$, and extremely large (>4.0) [50]. In addition, the upper and lower $95 \%$ confidence intervals of the difference $(95 \% \mathrm{CI})$ were calculated for the corresponding variation. The level of statistical significance was set at $p \leq 0.05$.

\section{Results}

Table 1 presents the physical performances recorded during different conditions.

\subsection{Taekwondo-Specific Agility Test}

The results showed a significant condition effect $\left(\mathrm{F}_{4,36}=35.376 ; p<0.001 ; \eta_{\mathrm{p}}{ }^{2}=0.96\right)$, with CAF + CA condition resulting in better performance compared with PL + NoCA (95\% $\mathrm{CI}=$ from -0.913 to $-0.403 ; \mathrm{d}=-1.46 ; p<0.001), \mathrm{CAF}+\mathrm{NoCA}(95 \% \mathrm{CI}=$ from -0.579 to $-0.198 ; \mathrm{d}=-0.96 ; p<0.001), \mathrm{PL}+\mathrm{CA}(95 \% \mathrm{CI}=$ from -0.435 to $-0.073 ; \mathrm{d}=-0.63$; $p=0.006)$, and the control $(95 \% \mathrm{CI}=$ from -0.931 to $-0.443 ; \mathrm{d}=-1.95 ; p<0.001)$ conditions. Moreover, PL + CA condition elicited better performances compared with PL + NoCA (95\% $\mathrm{CI}=$ from -0.596 to $-0.239 ; \mathrm{d}=-0.81 ; p<0.001), \mathrm{CAF}+\mathrm{NoCA}(95 \% \mathrm{CI}=$ from -0.227 to $-0.042 ; \mathrm{d}=-0.30 ; p=0.004)$, and control $(95 \% \mathrm{CI}=$ from -0.646 to $-0.220 ; \mathrm{d}=-1.06$; $p<0.001)$ conditions. In addition, $\mathrm{CAF}+\mathrm{NoCA}$ resulted in lower TSAT time in comparison with PL + NoCA $(95 \% \mathrm{CI}=$ from -0.449 to $-0.090 ; \mathrm{d}=-0.54 ; p=0.004)$ and the control $(95 \% \mathrm{CI}=$ from -0.501 to $-0.096 ; \mathrm{d}=-0.73 ; p=0.004)$ conditions. Similarly, there was a significant sex effect $\left(\mathrm{F}_{1,9}=11.398 ; p=0.008 ; \eta_{\mathrm{p}}{ }^{2}=0.559\right)$, with lower TSAT time in males compared with females $(95 \% \mathrm{CI}=$ from -1.220 to $-0.241 ; \mathrm{d}=-1.70 ; p=0.008)$. 
Table 1. Physical performances during taekwondo-specific tests following different conditions (values are mean $\pm \mathrm{SD} ; n=20)$.

\begin{tabular}{|c|c|c|c|c|c|c|c|}
\hline & & $\mathrm{PL}+\mathrm{NoCA}$ & $\mathrm{CAF}+\mathrm{NoCA}$ & $\mathrm{PL}+\mathrm{CA}$ & $\mathrm{CAF}+\mathrm{CA}$ & Control & Overall \\
\hline \multirow{3}{*}{ TSAT (s) } & $M$ & $5.7 \pm 0.5$ & $5.5 \pm 0.5$ & $5.3 \pm 0.5$ & $5.1 \pm 0.4$ & $6.0 \pm 0.2$ & $5.5 \pm 0.4^{£}$ \\
\hline & $\mathrm{F}$ & $6.6 \pm 0.5$ & $6.3 \pm 0.4$ & $6.2 \pm 0.4$ & $5.8 \pm 0.4$ & $6.3 \pm 0.5$ & $6.2 \pm 0.4$ \\
\hline & Overall & $6.1 \pm 0.5$ & $5.9 \pm 0.4^{\alpha}$ & $5.7 \pm 0.5^{\$, \S}$ & $5.5 \pm 0.4^{*, \neq}$ & $6.2 \pm 0.3$ & $5.9 \pm 0.4$ \\
\hline \multirow{3}{*}{ FSKT-10s $(n)$} & $M$ & $25 \pm 2$ & $27 \pm 2$ & $27 \pm 2$ & $29 \pm 2$ & $24 \pm 2$ & $27 \pm 2 d$ \\
\hline & $\mathrm{F}$ & $23 \pm 1$ & $24 \pm 1^{b, c}$ & $24 \pm 1^{a}$ & $26 \pm 1 *$ & $22 \pm 1$ & $24 \pm 1$ \\
\hline & Overall & $24 \pm 2$ & $25 \pm 1$ & $26 \pm 1$ & $28 \pm 1 *$ & $23 \pm 1$ & $25 \pm 1$ \\
\hline \multirow{3}{*}{$\begin{array}{l}\text { FSKT-mult (kicks' } \\
\text { number) }(n)\end{array}$} & $M$ & $117 \pm 7^{\mathrm{h}}$ & $121 \pm 8$ & $126 \pm 4$ & $138 \pm 7^{f}$ & $107 \pm 6^{g}$ & $122 \pm 6^{\mathrm{d}}$ \\
\hline & $\mathrm{F}$ & $105 \pm 6$ & $110 \pm 10$ & $111 \pm 9$ & $119 \pm 6^{f}$ & $95 \pm 10$ & $108 \pm 8$ \\
\hline & Overall & $111 \pm 6$ & $116 \pm 9 *$ & $118 \pm 6^{*, \mathrm{e}}$ & $128 \pm 7^{*}$ & $101 \pm 8$ & $115 \pm 7$ \\
\hline \multirow{3}{*}{ FSKT-mult (DI) (\%) } & $M$ & $9 \pm 2$ & $6 \pm 3$ & $7 \pm 2$ & $4 \pm 1$ & $11 \pm 3$ & $7 \pm 2^{d}$ \\
\hline & $\mathrm{F}$ & $10 \pm 2$ & $8 \pm 2$ & $7 \pm 4$ & $6 \pm 3$ & $13 \pm 4$ & $9 \pm 3$ \\
\hline & Overall & $10 \pm 2^{i}$ & $7 \pm 2^{i}$ & $7 \pm 3^{i}$ & $5 \pm 2^{*, \S}$ & $12 \pm 3$ & $8 \pm 2$ \\
\hline
\end{tabular}

* Main effect of condition: CAF + CA elicited better performance than CAF + NoCA, PL + NoCA, and control conditions at $p<0.001 ; \neq$ main effect of condition: CAF + CA elicited better performance than PL $+\mathrm{CA}$ at $p<0.01$; $\$$ main effect of condition: significantly better than PL + NoCA and control at $p<0.001 ;$; main effect of condition: better performance than CAF + NoCA at $p<0.05 ;^{\alpha}$ main effect of condition: better than PL + NoCA and control conditions at $p=0.004 ;{ }^{£}$ main effect of sex: better performance for males compared with females at $p=0.008$ ${ }^{\mathrm{a}}$ main effect of condition: better performance in PL + CA compared with PL + NoCA at $p<0.01{ }^{\mathrm{b}}$ main effect of condition: better performance than PL + NoCA at $p=0.005 ;{ }^{\mathrm{c}}$ main effect of condition: better performance than control condition at $p=0.007 ; \mathrm{d}$ main effect of sex: males elicited better performance than females at $p<0.001$; e: main effect of condition: better performance than PL + NoCA at $p=\langle 0.05$; $\mathrm{f}$ : interaction effect between condition and sex: better performance for females in CAF + CA or for males in CAF + CA at $p<0.001$; $\mathrm{g}$ interaction effect between condition and sex: males in control condition elicited lower values compared with other conditions at $p<0.001 ; \mathrm{h}$ interaction effect between condition and sex: males elicited higher values than females in PL + NoCA, CAF + NoCA, PL + CA, and CAF + CA at $p<0.001 ;{ }^{i}$ main effect of condition: better performance than control condition at $p<0.005$. TSAT-taekwondo-specific agility test; FSKT-10s-10 s frequency speed of kick test; FSKT-mult-multiple frequency speed of kick test; DI—decrement index; PL—placebo; CAF: caffeine; CA: conditioning activity; $n=$ number of techniques.

\subsection{Frequency Speed of Kick Test}

There was a significant condition effect $\left(\mathrm{F}_{4,36}=79.844 ; p<0.001 ; \eta_{\mathrm{p}}^{2}=0.982\right)$, with CAF + CA condition resulting in better performance compared with PL + NoCA $(95 \%$ CI $=$ from 3 to $5 ; \mathrm{d}=2.5 ; p<0.001), \mathrm{CAF}+\operatorname{NoCA}(95 \% \mathrm{CI}=$ from 2 to $4 ; \mathrm{d}=1.97 ; p<0.001)$, $\mathrm{PL}+\mathrm{CA}(95 \% \mathrm{CI}=$ from 1 to $3 ; \mathrm{d}=1.53 ; p<0.001)$, and control $(95 \% \mathrm{CI}=$ from 3 to 6 ; $\mathrm{d}=3.58 ; p<0.001)$ conditions. Moreover, $\mathrm{PL}+\mathrm{CA}$ condition resulted in better performance compared with PL + NoCA (95\% CI = from 1 to $2 ; \mathrm{d}=1.12 ; p<0.001)$, and the control $(95 \% \mathrm{CI}=$ from 1 to $4 ; \mathrm{d}=1.89 ; p=0.001)$ conditions. In addition, CAF + NoCA condition resulted in better performance compared with $\mathrm{PL}+\mathrm{NoCA}(95 \% \mathrm{CI}=$ from 0.3 to $2 ; \mathrm{d}=0.67$; $p=0.005)$ and control ( $95 \% \mathrm{CI}=$ from 0.5 to $3 ; \mathrm{d}=1.34 ; p=0.007)$ conditions. Similarly, results showed a significant sex effect $\left(\mathrm{F}_{1,9}=28.551 ; p<0.001 ; \eta_{\mathrm{p}}{ }^{2}=0.76\right)$, with better performance in males than females $(95 \% \mathrm{CI}=$ from 2 to $4 ; \mathrm{d}=1.78 ; p<0.001)$.

\subsection{Multiple Frequency Speed of Kick Test}

\subsubsection{Total Number of Techniques}

There was a significant condition effect $\left(\mathrm{F}_{4,90}=28.984 ; p<0.001 ; \eta_{\mathrm{p}}{ }^{2}=0.563\right)$, with a higher total number of techniques in the CAF + CA condition compared with PL + NoCA $(95 \% \mathrm{CI}=$ from 11 to $24 ; \mathrm{d}=1.78 ; p<0.001), \mathrm{CAF}+\mathrm{NoCA}(95 \% \mathrm{CI}=$ from 6 to $19 ; \mathrm{d}=1.61 ;$ $p<0.01), \mathrm{PL}+\mathrm{CA}(95 \% \mathrm{CI}=$ from 4 to $16 ; \mathrm{d}=1.52 ; p<0.001)$, and the control $(95 \% \mathrm{CI}=$ from 16 to $29 ; \mathrm{d}=3.7 ; p<0.001)$ conditions. Moreover, compared with control condition, the total number of techniques was significantly higher in the PL $+\mathrm{CA}(95 \% \mathrm{CI}=$ from 6 to $19 ; \mathrm{d}=2.36 ; p<0.001)$ and $\mathrm{CAF}+\operatorname{NoCA}(95 \% \mathrm{CI}=$ from 3 to $16 ; \mathrm{d}=1.67 ; p<0.001)$ conditions. Likewise, PL + CA condition induced higher values compared with PL + NoCA condition $(95 \% \mathrm{CI}=$ from 1 to $14 ; \mathrm{d}=1.20 ; p=0.010)$. Furthermore, a significant sex effect 
was found $\left(\mathrm{F}_{1,90}=66.815 ; p<0.001 ; \eta_{\mathrm{p}}{ }^{2}=0.426\right)$, with better performance in males than females $(95 \% \mathrm{CI}=$ from 9 to $14 ; \mathrm{d}=1.83 ; p<0.001)$. Moreover, there was an interaction effect between condition and $\operatorname{sex}\left(\mathrm{F}_{4,90}=3.627 ; p=0.009 ; \eta_{\mathrm{p}}{ }^{2}=0.414\right)$, with females in CAF + CA eliciting higher values compared with PL + NoCA and control conditions (95\% CI $=$ both from 5 to 24 ; both $\mathrm{d}=2.49$; both $p<0.001$ ) and males in CAF + CA resulting in higher values compared with PL + NoCA (95\% CI = from 5 to $24 ; \mathrm{d}=3.28 ; p<0.001), \mathrm{CAF}+$ NoCA $(95 \% \mathrm{CI}=$ from 5 to $24 ; \mathrm{d}=2.34 ; p<0.001), \mathrm{PL}+\mathrm{CA}(95 \% \mathrm{CI}=$ from 5 to $24 ; \mathrm{d}=2.31$; $p<0.001)$, and control $(95 \% \mathrm{CI}=$ from 5 to $24 ; \mathrm{d}=4.96 ; p<0.001)$ conditions, and control condition for males eliciting lower values compared with PL + NoCA $(95 \% \mathrm{CI}=$ from -19 to $-1 ; \mathrm{d}=-1.61 ; p=0.023), \mathrm{CAF}+\operatorname{NoCA}(95 \% \mathrm{CI}=$ from -23 to $-5 ; \mathrm{d}=-2.01 ; p<0.001)$, and PL + CA (95\% CI $=$ from -28 to $-10 ; \mathrm{d}=-3.73 ; p<0.001)$ (Table 1). Moreover, males elicited higher values compared with females in PL + NoCA (95\% CI = from 6 to 18; $\mathrm{d}=2.06 ; p<0.001), \mathrm{CAF}+\operatorname{NoCA}(95 \% \mathrm{CI}=$ from 4 to $17 ; \mathrm{d}=1.23 ; p<0.001), \mathrm{PL}+\mathrm{CA}(95 \%$ $\mathrm{CI}=$ from 8 to $21 ; \mathrm{d}=2.16 ; p=0.001)$, and $\mathrm{CAF}+\mathrm{CA}(95 \% \mathrm{CI}=$ from 12 to $25 ; \mathrm{d}=2.96$; $p<0.001)$ conditions.

\subsubsection{Decrement Index}

There was a significant condition effect $\left(\mathrm{F}_{4,90}=17.859 ; p<0.001 ; \eta_{\mathrm{p}}{ }^{2}=0.442\right)$, with lower DI in CAF + CA condition compared with PL + NoCA (95\% CI $=$ from -7 to -2 ; $\mathrm{d}=-2.46 ; p<0.001), \mathrm{CAF}+\operatorname{NoCA}(95 \% \mathrm{CI}=$ from -5 to $-0.01 ; \mathrm{d}=-1.07 ; p=0.049)$, and the control $(95 \% \mathrm{CI}=$ from -9 to $-4 ; \mathrm{d}=-2.56 ; p<0.001)$ conditions. Moreover, compared with control condition, DI was significantly lower in the PL + NoCA (95\% CI = from -7.987 to $-0.881 ; \mathrm{d}=-0.95 ; p=0.013), \mathrm{CAF}+\operatorname{NoCA}(95 \% \mathrm{CI}=$ from -6.859 to $-1.833 ; \mathrm{d}=-1.54$; $p=0.001)$, and PLA + CA $(95 \% \mathrm{CI}=$ from -7.987 to $-0.881 ; \mathrm{d}=-1.42 ; p=0.013)$ conditions. Furthermore, a significant sex effect was found $\left(\mathrm{F}_{1,90}=4.990 ; p<0.001 ; \eta_{\mathrm{p}}{ }^{2}=0.053\right)$, with better performance in males than females (95\% CI = from 10 to 17 ; $\mathrm{d}=1.83 ; p<0.001$ ).

Table 2 presents the psychological responses, and Table 3 shows perceived exertion and recovery scores through different conditions.

Table 2. Psychological responses before and after different conditions (values are mean $\pm \mathrm{SD} ; n=20$ ).

\begin{tabular}{|c|c|c|c|c|c|c|c|c|c|c|c|c|}
\hline & & \multicolumn{5}{|c|}{ Before } & \multicolumn{5}{|c|}{ After } & \multirow[b]{2}{*}{ Overall } \\
\hline & & $\begin{array}{c}\text { PL + } \\
\text { NoCA }\end{array}$ & $\begin{array}{l}\mathrm{CAF}+ \\
\mathrm{NoCA}\end{array}$ & $\begin{array}{c}\mathrm{PL}+ \\
\mathrm{CA}\end{array}$ & $\underset{\mathrm{CA}}{\mathrm{CAF}}+$ & Overall & $\begin{array}{c}\text { PL + } \\
\text { NoCA }\end{array}$ & $\begin{array}{l}\mathrm{CAF}+ \\
\mathrm{NoCA}\end{array}$ & $\begin{array}{c}\mathrm{PL}+ \\
\mathrm{CA}\end{array}$ & $\underset{\mathrm{CA}}{\mathrm{CAF}}+$ & Overall & \\
\hline \multirow{3}{*}{$\begin{array}{c}\text { MPSS } \\
\text { (a.u.) }\end{array}$} & $\mathrm{M}$ & $53 \pm 9$ & $48 \pm 4$ & $45 \pm 6$ & $47 \pm 7$ & $48 \pm 7$ & $56 \pm 9^{c}$ & $55 \pm 6^{c}$ & $49 \pm 6$ & $53 \pm 6$ & $53 \pm 7$ & $51 \pm 7$ \\
\hline & $\mathrm{F}$ & $44 \pm 7$ & $49 \pm 9$ & $46 \pm 2$ & $43 \pm 4$ & $45 \pm 5$ & $49 \pm 9$ & $46 \pm 2^{e}$ & $43 \pm 4^{d}$ & $47 \pm 7^{\mathrm{d}}$ & $46 \pm 5$ & $46 \pm 5$ \\
\hline & Overall & $48 \pm 8$ & $49 \pm 6^{a}$ & $45 \pm 4$ & $45 \pm 5$ & $47 \pm 6$ & $52 \pm 9$ & $53 \pm 8$ & $46 \pm 5$ & $50 \pm 6$ & $50 \pm 7^{b}$ & $49 \pm 6$ \\
\hline \multirow{3}{*}{$\begin{array}{l}\text { SVS } \\
\text { (a.u.) }\end{array}$} & $\mathrm{M}$ & $29 \pm 4$ & $31 \pm 3^{g}$ & $27 \pm 5$ & $29 \pm 4^{g}$ & $29 \pm 4$ & $28 \pm 10$ & $33 \pm 4$ & $28 \pm 6$ & $34 \pm 4$ & $31 \pm 6$ & $30 \pm 5^{f}$ \\
\hline & $\mathrm{F}$ & $24 \pm 6$ & $27 \pm 3$ & $27 \pm 2$ & $24 \pm 4$ & $26 \pm 4$ & $25 \pm 9$ & $30 \pm 5$ & $27 \pm 3$ & $29 \pm 3$ & $28 \pm 5$ & $27 \pm 4$ \\
\hline & Overall & $26 \pm 5$ & $29 \pm 3$ & $27 \pm 3^{a}$ & $27 \pm 4$ & $27 \pm 4$ & $26 \pm 10$ & $31 \pm 5$ & $28 \pm 4$ & $32 \pm 4$ & $29 \pm 6$ & $28 \pm 5$ \\
\hline \multirow{3}{*}{$\begin{array}{c}\text { FS } \\
\text { (a.u.) }\end{array}$} & $\mathrm{M}$ & $2 \pm 1$ & $2 \pm 1^{g}$ & $1 \pm 2$ & $1 \pm 3^{g}$ & $2 \pm 2$ & $2 \pm 2$ & $3 \pm 2^{g}$ & $1 \pm 2$ & $4 \pm 1^{g}$ & $2 \pm 2$ & $2 \pm 2^{f}$ \\
\hline & $\mathrm{F}$ & $1 \pm 1$ & $2 \pm 1$ & $1 \pm 2$ & $0.3 \pm 1$ & $1 \pm 1$ & $1 \pm 3$ & $2 \pm 2$ & $1 \pm 3$ & $2 \pm 1$ & $2 \pm 2$ & $1 \pm 2$ \\
\hline & Overall & $2 \pm 1$ & $2 \pm 1$ & $1 \pm 2$ & $1 \pm 2$ & $1 \pm 1$ & $1 \pm 3$ & $2 \pm 2$ & $1 \pm 2$ & $3 \pm 1$ & $2 \pm 2$ & $2 \pm 2$ \\
\hline
\end{tabular}

${ }^{\text {a }}$ Main effect of condition: different from PL + NoCA and PL + CA at $p<0.05 ;{ }^{\mathrm{b}}$ main effect of time of measurement better performance after compared with before at $p<0.05 ;{ }^{\mathrm{c}}$ interaction effect between sex and time: males elicited higher values before compared with before for PL + NoCA and CAF + NoCA conditions at $p<0.05$; ${ }^{\mathrm{d}}$ interaction effect between sex and time: females elicited higher values after compared with before for PL + CA and CAF $+\mathrm{CA}$ conditions at $p<0.05$; ${ }^{\mathrm{e}}$ interaction effect between sex and time: females elicited higher values after CAF + NoCA compared with PL + NoCA and PL + CA at $p<0.01 ;{ }^{\mathrm{f}}$ main effect of sex: males elicited higher values than females at $p<0.01$; $\mathrm{g}$ : interaction effect between sex and condition: higher scores for males than females in CAF + NoCA and CAF + CA conditions at $p<0.05$. a.u.-arbitrary unit; M-male; F-female; MPSS-Mood and Physical Symptoms Scale; SVS—Subjective Vitality Scale; FS—Feeling Scale; PL—placebo; CAF—caffeine; CA-conditioning activity. 
Table 3. Rating of perceived exertion and perceived recovery status scores across different conditions (values are mean $\pm \mathrm{SD} ; n=20$ )

\begin{tabular}{cccccccc}
\hline & & PL + NoCA & CAF + NoCA & PL + CA & CAF + CA & Control & Overall \\
\hline \multirow{2}{*}{ RPE } & M & $7.5 \pm 1.5$ & $7.4 \pm 0.8$ & $7.1 \pm 1.2$ & $7.6 \pm 1.0$ & $7.0 \pm 1.1$ & $7.3 \pm 1.1$ \\
(a.u.) & F & $6.9 \pm 1.5$ & $7.1 \pm 1.4$ & $7.9 \pm 1.2$ & $7.6 \pm 1.2$ & $7.7 \pm 1.0$ & $7.4 \pm 1.2$ \\
& Overall & $7.2 \pm 1.5$ & $7.25 \pm 1.1$ & $7.5 \pm 1.2$ & $7.6 \pm 1.1$ & $7.4 \pm 1.0$ & $7.4 \pm 1.2$ \\
PRS (a.u.) & $\mathrm{M}$ & $2.6 \pm 0.8$ & $2.7 \pm 1.2$ & $2.7 \pm 1.5$ & $3.0 \pm 1.7$ & $3.2 \pm 1.3$ & $2.8 \pm 1.3$ \\
& $\mathrm{~F}$ & $2.7 \pm 1.5$ & $2.7 \pm 2.1$ & $2.0 \pm 0.7$ & $2.1 \pm 0.7$ & $2.8 \pm 0.8$ & $2.5 \pm 1.2$ \\
& Overall & $2.7 \pm 1.2$ & $2.7 \pm 1.6$ & $2.4 \pm 1.1$ & $2.6 \pm 1.2$ & $3.0 \pm 1.1$ & $2.7 \pm 1.2$ \\
\hline
\end{tabular}

a.u.—arbitrary unit; RPE—rating of perceived exertion; PRS—-perceived recovery status; PL—placebo; CAFcaffeine; $\mathrm{CA}-$ conditioning activity; $\mathrm{M}-$ male; $\mathrm{F}-$ female.

\subsection{Mood and Physical Symptoms Scale}

Results showed that there was a significant condition effect $\left(\mathrm{F}_{1 \cdot 365,12 \cdot 287}=14.427\right.$; $\left.p=0.002 ; \eta_{\mathrm{p}}^{2}=0.861\right)$, with CAF + NoCA resulting in higher scores compared with the $\mathrm{PL}+\operatorname{NoCA}(95 \% \mathrm{CI}=$ from 2 to $8 ; \mathrm{d}=0.34 ; p=0.002)$ and the PL $+\mathrm{CA}(95 \% \mathrm{CI}=$ from 2 to $14 ; \mathrm{d}=0.61 ; p=0.009)$. Similarly, there was a significant time of measurement effect $\left(\mathrm{F}_{1,9}=10.829 ; p=0.009 ; \eta_{\mathrm{p}}{ }^{2}=0.546\right)$, with higher values in post- than pre-conditions $(95 \%$ $\mathrm{CI}=$ from 1 to $5 ; \mathrm{d}=0.54 ; p=0.009)$. There was an interaction effect between condition, sex, and time of measurement $\left(\mathrm{F}_{1 \cdot 461,13 \cdot 149}=5.485 ; p=0.004 ; \eta_{\mathrm{p}}{ }^{2}=0.379\right)$, with males eliciting higher values post compared with pre for PL + NoCA and CAF + NoCA conditions $(95 \% \mathrm{CI}$ $=$ from 1 to 14 and 1 to $12 ; \mathrm{d}=0.28$ and 1.208; $p=0.024$ and 0.034 , respectively). Moreover, females presented higher values post compared with pre for PL + CA and CAF $+C A$ conditions $(95 \% \mathrm{CI}=$ from 1 to 12 and from 1 to $8 ; \mathrm{d}=0.65$ and $0.72 ; p=0.038$ and 0.036 , respectively). Additionally, females elicited higher values post CAF + NoCA compared with PL + NoCA and PL + CA (95\% CI = from 1 to 12 and from 5 to $16 ; \mathrm{d}=0.716$ and 0.43 ; $p=0.01$ and 0.001 , respectively) (Table 2).

\subsection{Subjective Vitality Scale}

There was a significant condition effect $\left(\mathrm{F}_{3,27}=10.313 ; p=0.006 ; \eta_{\mathrm{p}}{ }^{2}=0.815\right)$, with $\mathrm{PL}+$ CA condition resulting in lower scores than $\mathrm{PL}+\mathrm{NoCA}(95 \% \mathrm{CI}=$ from -6 to $-1 ; \mathrm{d}=-0.2$; $p=0.01)$, and CAF + NoCA $(95 \% \mathrm{CI}=$ from -9 to $-2 ; \mathrm{d}=-0.67 ; p=0.004)$ conditions. In addition, there was a significant sex effect $\left(\mathrm{F}_{1,9}=6.889 ; p=0.028 ; \eta_{\mathrm{p}}{ }^{2}=0.434\right)$, with higher values for males than females $(95 \% \mathrm{CI}=$ from 0.4 to $5 ; \mathrm{d}=0.72 ; p=0.028)$. There was a significant interaction effect between sex and condition $\left(\mathrm{F}_{3,27}=4.743 ; p=0.041 ; \eta_{\mathrm{p}}{ }^{2}=0.67\right)$, with higher scores for males than females in CAF + NoCA and CAF + CA conditions (95\% $\mathrm{CI}=$ from 2 to 9 and from 0.004 to $7 ; \mathrm{d}=1.015$ and $1.52 ; p=0.007$ and 0.050 , respectively).

\subsection{Feeling Scale}

Results showed a sex effect $\left(\mathrm{F}_{1,9}=7.494 ; p=0.020 ; \eta_{\mathrm{p}}{ }^{2}=0.469\right)$, with males eliciting higher scores than females $(95 \% \mathrm{CI}=$ from 0.1 to $1 ; \mathrm{d}=0.33 ; p=0.020)$. Moreover, there was a significant interaction effect between condition and $\operatorname{sex}\left(\mathrm{F}_{3,7}=8.207 ; p<0.001 ; \eta_{\mathrm{p}}{ }^{2}=0.477\right)$, with males eliciting higher values than females in CAF + NoCA and CAF + CA $(95 \% \mathrm{CI}=$ from 0.1 to 2 and from 1 to $3 ; \mathrm{d}=0.14$ and $0.93 ; p=0.037$ and $p<0.001$, respectively).

\section{Discussion}

The purpose of this study was to investigate the effects of combining CAF and CA on psychological responses and specific physical performances in young taekwondo athletes. The present study showed that combining CAF with plyometric exercise during warm-up improved physical performance in all specific tests (i.e., TSAT, FSKT-10s, and FSKT-mult (total number of techniques)) compared with the other conditions. Moreover, males elicited greater physical and psychological responses compared with females. Furthermore, the $\mathrm{CAF}+\mathrm{NoCA}$ condition resulted in more positive psychological responses (i.e., higher 
MPSS and SVS scores) than the placebo conditions. However, RPE and PRS did not differ across conditions.

The present study showed better physical performances recorded during TSAT, FSKT10s, and FSKT-mult following CAF supplementation and CA. It seems difficult to compare our results to other studies since no previous research has examined the acute effects of $\mathrm{CAF}$ and CA combination in combat sports. However, to our current knowledge, there was only one previous study [18] that has examined the combined effects of CAF and plyometric exercises in the male soccer players' performance. This study showed that the combined condition resulted in greater jumping performance following plyometric and sled towing stimuli with $5 \mathrm{mg} / \mathrm{kg}$ of CAF. Despite the difference between our study and the aforementioned one in terms of participants, testing procedure, and sport modality, its findings support our results because lower body performance's improvement needs greater explosive power [3].

Regarding the effectiveness of CAF and CA separately used, our results are in agreement with those reported in previous studies in combat sports. In fact, the effectiveness of plyometric-based CA to improve subsequent physical performance has been confirmed in previous studies investigating other combat sports [23-25]. In karate athletes, Margaritopoulos et al. [24] showed that three sets of five tuck jumps followed by $5 \mathrm{~min}$ interval induced a 3.5\% improvement in jump height. In judo athletes, similar results were found by Miarka et al. [25], who reported a $12 \%$ increase in the number of throws during the special judo fitness test when athletes were submitted to ten sets of three consecutive jumps followed by $3 \mathrm{~min}$ of rest. However, da Silva Santos et al. [27] did not report improvement in kicking performance during the FSKT-10s following three sets of ten vertical jumps above $40 \mathrm{~cm}$ barrier even when $10 \mathrm{~min}$ of rest was given. In addition, Castro-Garrido et al. [26] did not find significant differences in the total number of kicks during the FSKT-mult $10 \mathrm{~min}$ after performing three sets of ten jumps above $20 \mathrm{~cm}$. This contradiction could be related to the difference in the methodological approaches from one side and to the inter-individual variation from the other side. Moreover, in taekwondo, speed is a key element in the Bandal Tchagui technique [27]. Since the rectus femoris muscle is the most recruited muscle in this technique [2], the performance enhancement following the plyometric CA was mainly located in the quadriceps muscles [51]. The main mechanism under this enhancement is probably due to a reduction in the pennation angle, which improves force transmission to the tendon [18].

Furthermore, the physical improvements following CAF supplementation without CA were similar to those reported in previous studies. In fact, with male taekwondo athletes, it was reported that $5 \mathrm{mg} / \mathrm{kg}$ of CAF ingestion was effective in enhancing reaction time $1 \mathrm{~h}$ following supplementation [9,11]. Using a similar dose of CAF (i.e., $3 \mathrm{mg} / \mathrm{kg}$ ), Diaz-Lara et al. [39] reported that maximal lower body strength production was improved in elite Brazilian jiu-jitsu athletes. In the present study, the impact of CAF on physical performances may be explained by both peripheral and central mechanisms. More specifically, at the peripheral level, CAF increased the bioavailability of calcium in the myoplasm [6], which positively affected the energy release by the muscle, explaining then the ergogenic effects observed in both agility and kicking performances. Furthermore, CAF serves as an adenosine antagonist at the central level, boosting neurotransmitter production and nervous system activation [5].

Likewise, scoring more points is the main goal in taekwondo competitions [43]. To achieve this aim, elite taekwondo competitors need to perform strong and fast kicks [2] with less exhaustion [43]. However, in repeated high-intensity actions, fatigue has a detrimental influence on kick time and impact [52]. In the present study, the decrease in fatigue rate indicated by the DI could confirm the effectiveness of the plyometric CA on taekwondo-specific performance. This result was not in accordance with those previously reported in taekwondo athletes [26,43]. The discrepancy could be related to the difference in the methodological approaches (i.e., the CA mode and the jump height used in each trial). For the CAF effect, it has been argued that the most pronounced effects of CAF 
are evident in delaying the onset of fatigue [9]. This was confirmed in our study as CAF supplementation decreased the decrement index. Similar results were reported by the study of Astley et al. [8], which assessed the influence of acute ingestion of $4 \mathrm{mg} / \mathrm{kg}$ of CAF on SJFT and showed an increase in performance $60 \mathrm{~min}$ post-supplementation by achieving a greater number of throws (31\%) and reducing the fatigue index by $22.29 \%$. Moreover, in taekwondo, $5 \mathrm{mg} / \mathrm{kg}$ of CAF was sufficient to improve performance in a specific task and effective in delaying fatigue during successive taekwondo bouts [11] and after strenuous tasks [9]. Indeed, Lopes-Silva et al. [13] reported increased glycolytic activation during taekwondo simulated match after the ingestion of $5 \mathrm{mg} / \mathrm{kg}$ of CAF $1 \mathrm{~h}$ before the task. Thus, a higher glycolytic activation may also be a contributing factor to improved performance in our taekwondo-specific tests.

CAF and CA are two different conditioning strategies, and there is a common explanation of performance enhancement following their combined application. In fact, the decrease in the fatigue level could be attributed to an enhancement in neuromuscular efficiency following CAF supplementation [9] and CA application [53], which increased the recruitment of high-threshold motor units [21] or even increased the activation of synergists [54], resulting in greater intra- and inter-muscle coordination $[55,56]$.

It is well known that the ergogenic potential of CAF is established by its direct action on the central nervous system, leading to improved alertness and reaction time and reducing the rating of perceived exertion [57]. Although physical performances were increased after the combined use of CA and CAF, no differences between conditions were found for RPE and PRS scores. This could indicate that all experimental conditions resulted in similar perceived exertion and recovery. This result was similar to those reported in previous studies in combat sports, which revealed the lack of significant caffeine effect $[11,13]$ and CA $[27,43]$ on these parameters. The fact that all our tasks involved all-out efforts is also a fact to explain the absence of difference between conditions regarding RPE. However, other interventions with CAF ingestion [8,58] or after performing a CA [23] showed a reduced RPE in both male and female athletes.

Considering the psychological responses, MPSS, FS, and SVS scores were higher after caffeine ingestion compared with the placebo condition. These results are in accordance with those previously reported [34,35], showing that $6 \mathrm{mg} / \mathrm{kg}$ of CAF ingestion $60 \mathrm{~min}$ prior to testing enhanced positive mood components (i.e., vigor and tension) and increased subjective vitality profile in elite athletes. These results suggest that CAF intake leads to the finest emotional state to perform a physical task and prepares the athlete to face a severe mental effort [34]. The effects of CAF on these parameters may be related to the enhancement of brain activation [34]. Since that adenosine formation is primarily regulated by energy deprivation, the caffeine antagonism of adenosine signaling can override this regulation, resulting in fatigue reduction and increased pleasure even when energy levels are low [36].

The current study showed that males elicited significantly better performances than females. This result is in accordance with previous studies $[17,28]$, which reported that the ergogenic aid of caffeine declines within females in anaerobic exercise tests. In fact, it was shown that the improvement in strength and power performance is more pronounced in males compared with females [17]. However, it was not the case for isometric contractions, where the ergogenic effect of CAF (i.e., $6 \mathrm{mg} / \mathrm{kg}$ ) on muscle power and muscle endurance did not show a sex difference [6]. In this context, it was expected that CYP1A2 and ADORA2A enzymes modulate the rate of CAF metabolism, which determines the genotype characteristics and causes different responses to CAF [16]. However, even though they have the same genotypes, it has been suggested that females require a longer time to metabolize CAF than males [15]. This fact could be explained by the greater half-life of CAF in females than in males [14]. Moreover, the effect of CAF was reported to be greater in individuals with larger muscle mass [59]. Therefore, the higher performances recorded by males than those by females could be explained by this fact, as males are stronger than females [58]. Supporting our findings, previous studies showed that, with the same dose 
of CAF, males had greater ergogenic impact than females, particularly regarding power and speed [29]. Concerning the impact of sex on psychological responses, results showed that more positive affect and vitality profiles were presented by males than females in CAF $+\mathrm{NoCA}$ and CAF + CA conditions. In this consideration, studies applying neuro- and psycho-pharmacological approaches suggested that males perceive lower somnolence and greater activation after supplementation compared with females [30]. Therefore, in line with what was recommended by Martins et al. [14], it is important to be cautious when extending male findings to females.

The improvement of physical performances and psychological responses following the combined conditions was not clear. However, the synergistic effect of CA and CAF ingestion suggested by Guerra Jr et al. [18] could explain our results. In fact, the positive action of CAF on MPSS and VS could improve the athletes' behaviors to exercise, which probably improves alertness and reaction time [57]. Furthermore, it was revealed that the effects of caffeine on cognition and brain activation are greater with low doses of caffeine than with moderate and high doses [60]. Thus, the $3 \mathrm{mg} / \mathrm{kg}$ ingested in the present study could be efficient to block the inhibitor effects of adenosine. At this time, the CA prepared the involved muscles for high-intensity movements through a variety of processes, which can include those mentioned above. Consequently, the reported outcomes might be the result of a mix of central and peripheral mechanisms. However, this explanation remains a theory that must be tested in future research.

Although this study led to a novel approach to enhance taekwondo athletes' performance, some limitations should be acknowledged. In fact, daily CAF consumption was not measured using objective markers (i.e., urine caffeine production, plasma caffeine, or caffeine metabolite levels). In addition, there has been no research into the mechanisms underlying the synergistic effects of CAF and CA, and genetic polymorphisms were not controlled to explain the results. Finally, the tests used are specific and could mimic the competition demands, but they did not provide information about athletes' tactical behaviors. Therefore, it is of great importance to investigate the effects of CAF and CA combination on taekwondo simulated competition.

\section{Conclusions}

Caffeine supplementation and conditioning activity are two effective strategies aiming to improve the physical performances and the psychological state of athletes. The present study showed the effectiveness of combining the effects of the low dose of caffeine ingestion (i.e., $3 \mathrm{mg} / \mathrm{kg}$ ) and a plyometric based-conditioning activity in enhancing the performance than their separate use. Specifically, $3 \mathrm{mg} / \mathrm{kg}$ of CAF is a safe dose and did not result in adverse effects that could impair taekwondo-specific performances. The synergistic effects of caffeine and conditioning activity could be an efficient strategy to prepare athletes to cope with physical and psychological stress during competitions and can serve to organize the pre-competitive routine or training session more effectively.

Author Contributions: Conceptualization, I.O., N.M., S.D., H.M., H.C., Z.S., A.B., E.B., H.N., L.P.A and E.F.; methodology, I.O., N.M., S.D., H.M., H.C., Z.S., A.B., E.B., H.N., L.P.A. and E.F.; software, I.O., N.M., S.D., H.M., H.C., Z.S., A.B., E.B., H.N., L.P.A. and E.F.; validation, I.O., N.M., S.D., H.M., H.C., Z.S., A.B., E.B., H.N., L.P.A. and E.F.; formal analysis, I.O., N.M., S.D., H.M., H.C., Z.S., A.B., E.B., H.N., L.P.A. and E.F.; investigation, I.O., N.M., S.D., H.M., H.C., Z.S., A.B., E.B., H.N., L.P.A. and E.F.; resources, I.O., N.M., S.D., H.M., H.C., Z.S., A.B., E.B., H.N., L.P.A. and E.F.; data curation, I.O., N.M., S.D., H.M., H.C., Z.S., A.B., E.B., H.N., L.P.A. and E.F.; writing-original draft preparation, I.O., N.M., S.D., H.M., H.C., Z.S., A.B., E.B., H.N., L.P.A. and E.F.; writing-review and editing, I.O., N.M., S.D., H.M., H.C., Z.S., A.B., E.B., H.N., L.P.A. and E.F.; visualization, I.O., N.M., S.D., H.M., H.C., Z.S., A.B., E.B., H.N., L.P.A. and E.F.; supervision, I.O., N.M., S.D., H.M., H.C., Z.S., A.B., E.B., H.N., L.P.A. and E.F.; project administration, I.O., N.M., S.D., H.M., H.C., Z.S., A.B., E.B., H.N., L.P.A. and E.F.; funding acquisition, I.O., N.M., S.D., H.M., H.C., Z.S., A.B., E.B., H.N., L.P.A. and E.F. All authors have read and agreed to the published version of the manuscript.

Funding: No external financial support has been received. 
Institutional Review Board Statement: The study was conducted in accordance with the Declaration of Helsinki and approved by the Ethical Committee for the Protection of Southern Persons (CPP SUD $\left.\mathrm{N}^{\circ} 0332 / 2021\right)$.

Informed Consent Statement: Informed consent was obtained from all subjects involved in the study.

Data Availability Statement: The data presented in this study are available on request from the corresponding authors.

Acknowledgments: The authors wish to thank all the athletes who volunteered within this study.

Conflicts of Interest: The authors declare no conflict of interest.

\section{Glossary}

$\begin{array}{ll}\text { CA } & \text { Conditioning activity (single condition) } \\ \text { CAF } & \text { Caffeine (single condition) } \\ \text { DI } & \text { Kick decrement index } \\ \text { FS } & \text { Feeling Scale } \\ \text { FSKT-mult } & \text { Multiple frequency speed of kick test } \\ \text { FSKT-10s } & \text { Frequency speed of kick test } \\ \text { MPSS } & \text { Mood and Physical Symptoms Scale } \\ \text { NoCA } & \text { Without conditioning activity (single condition) } \\ \text { PAP } & \text { Post-activation potentiation } \\ \text { PAPE } & \text { Post-activation performance enhancement } \\ \text { PL } & \text { Placebo (single condition) } \\ \text { PRS } & \text { Perceived recovery status } \\ \text { RPE } & \text { Rating of perceived exertion } \\ \text { SVS } & \text { Subjective Vitality Scale } \\ \text { TSAT } & \text { Taekwondo-specific agility test }\end{array}$

\section{References}

1. Bridge, C.A.; Ferreira da Silva Santos, J.; Chaabene, H.; Pieter, W.; Franchini, E. Physical and physiological profiles of taekwondo athletes. Sports Med. 2014, 44, 713-733. [CrossRef] [PubMed]

2. Tornello, F.; Capranica, L.; Chiodo, S.; Minganti, C.; Tessitore, A. Time-motion analysis of youth Olympic Taekwondo combats. J. Strength Cond. Res. 2013, 27, 223-228. [CrossRef] [PubMed]

3. Grgic, J.; Trexler, E.T.; Lazinica, B.; Pedisic, Z. Effects of caffeine intake on muscle strength and power: A systematic review and meta-analysis. J. Int. Soc. Sports Nutr. 2018, 15, 11. [CrossRef] [PubMed]

4. Davis, J.K.; Green, J.M. Caffeine and anaerobic performance: Ergogenic value and mechanisms of action. Sports Med. 2009, 39, 813-832. [CrossRef]

5. Davis, J.M.; Zhao, Z.; Stock, H.S.; Mehl, K.A.; Buggy, J.; Hand, G.A. Central nervous system effects of caffeine and adenosine on fatigue. Am. J. Physiol. Regul. Integr. Comp. Physiol. 2003, 284, R399-R404. [CrossRef]

6. Chen, H.Y.; Wang, H.S.; Tung, K.; Chao, H.H. Effects of Gender Difference and Caffeine Supplementation on Anaerobic Muscle Performance. Int. J. Sports Med. 2015, 36, 974-978. [CrossRef]

7. Lopez-Gonzalez, L.M.; Sanchez-Oliver, A.J.; Mata, F.; Jodra, P.; Antonio, J.; Dominguez, R. Acute caffeine supplementation in combat sports: A systematic review. J. Int. Soc. Sports Nutr. 2018, 15, 60. [CrossRef]

8. Astley, C.; Souza, D.; Polito, M. Acute Caffeine Ingestion on Performance in Young Judo Athletes. Pediatr. Exerc. Sci. 2017, 29, 336-340. [CrossRef]

9. Cortez, L.; Mackay, K.; Contreras, E.; Penailillo, L. Acute effect of caffeine ingestion on reaction time and electromyographic activity of the Dollyo Chagi round kick in taekwondo fighters. Rev. Int. Cienc. Deporte 2017, 13, 52-62. [CrossRef]

10. Merino Fernández, M.; Ruiz-Moreno, C.; Giráldez-Costas, V.; Gonzalez-Millán, C.; Matos-Duarte, M.; Gutiérrez-Hellín, J.; González-García, J. Caffeine Doses of $3 \mathrm{mg} / \mathrm{kg}$ Increase Unilateral and Bilateral Vertical Jump Outcomes in Elite Traditional Jiu-Jitsu Athletes. Nutrients 2021, 13, 1705. [CrossRef]

11. Santos, V.G.; Santos, V.R.; Felippe, L.J.; Almeida, J.W., Jr.; Bertuzzi, R.; Kiss, M.A.; Lima-Silva, A.E. Caffeine reduces reaction time and improves performance in simulated-contest of taekwondo. Nutrients 2014, 6, 637-649. [CrossRef] [PubMed]

12. De Azevedo, A.P.; Guerra, M.A.; Caldas, L.C.; Guimaraes-Ferreira, L. Acute Caffeine Ingestion did not Enhance Punch Performance in Professional Mixed-Martial Arts Athletes. Nutrients 2019, 11, 1422. [CrossRef] [PubMed]

13. Lopes-Silva, J.P.; Silva Santos, J.F.; Branco, B.H.; Abad, C.C.; Oliveira, L.F.; Loturco, I.; Franchini, E. Caffeine Ingestion Increases Estimated Glycolytic Metabolism during Taekwondo Combat Simulation but Does Not Improve Performance or Parasympathetic Reactivation. PLoS ONE 2015, 10, e0142078. [CrossRef] [PubMed] 
14. Martins, G.L.; Guilherme, J.; Ferreira, L.H.B.; de Souza-Junior, T.P.; Lancha, A.H., Jr. Caffeine and Exercise Performance: Possible Directions for Definitive Findings. Front. Sports Act. Living 2020, 2, 574854. [CrossRef]

15. Pickering, C. Caffeine, CYP1A2 genotype, and sports performance: Is timing important? Ir. J. Med. Sci. 2019, 188, 349-350. [CrossRef]

16. Southward, K.; Rutherfurd-Markwick, K.; Badenhorst, C.; Ali, A. The Role of Genetics in Moderating the Inter-Individual Differences in the Ergogenicity of Caffeine. Nutrients 2018, 10, 1352. [CrossRef]

17. Mielgo-Ayuso, J.; Marques-Jiménez, D.; Refoyo, I.; Del Coso, J.; León-Guereño, P.; Calleja-González, J. Effect of Caffeine Supplementation on Sports Performance Based on Differences Between Sexes: A Systematic Review. Nutrients 2019, $11,2313$. [CrossRef]

18. Guerra, M.A., Jr.; Caldas, L.C.; De Souza, H.L.; Vitzel, K.F.; Cholewa, J.M.; Duncan, M.J.; Guimarães-Ferreira, L. The acute effects of plyometric and sled towing stimuli with and without caffeine ingestion on vertical jump performance in professional soccer players. J. Int. Soc. Sports Nutr. 2018, 15, 51. [CrossRef]

19. Blazevich, A.J.; Babault, N. Post-activation Potentiation Versus Post-activation Performance Enhancement in Humans: Historical Perspective, Underlying Mechanisms, and Current Issues. Front. Physiol. 2019, 10, 1359. [CrossRef]

20. Cuenca-Fernandez, F.; Smith, I.C.; Jordan, M.J.; MacIntosh, B.R.; Lopez-Contreras, G.; Arellano, R.; Herzog, W. Nonlocalized postactivation performance enhancement (PAPE) effects in trained athletes: A pilot study. Appl. Physiol. Nutr. Metab. 2017, 42, 1122-1125. [CrossRef]

21. $\mathrm{Ng}, \mathrm{C}$. Y.; Chen, S.E.; Lum, D. Inducing postactivation potentiation with different modes of exercise. Strength Cond. J. 2020, 42, 63-81. [CrossRef]

22. Seitz, L.B.; Haff, G.G. Factors Modulating Post-Activation Potentiation of Jump, Sprint, Throw, and Upper-Body Ballistic Performances: A Systematic Review with Meta-Analysis. Sports Med. 2016, 46, 231-240. [CrossRef] [PubMed]

23. Lum, D. Effects of various warm-up protocol on special judo fitness test performance. J. Strength Cond. Res. 2019, 33, 459-465. [CrossRef] [PubMed]

24. Margaritopoulos, S.; Theodorou, A.; Methenitis, S.; Zaras, N.; Donti, O.; Tsolakis, C. The effect of plyometric exercises on repeated strength and power performance in elite karate athletes. J. Phys. Educ. Sport 2015, 15, 310.

25. Miarka, B.; Del Vecchio, F.B.; Franchini, E. Acute effects and postactivation potentiation in the Special Judo Fitness Test. J. Strength Cond. Res. 2011, 25, 427-431. [CrossRef]

26. Castro-Garrido, N.; Valderas-Maldonado, C.; Herrera-Valenzuela, T.; Ferreira Da Silva, J.; Guzmán-Muñoz, E.; Vásquez-Gómez, J.; Magnani Branco, B.; Zapata-Bastias, J.; López-Fuenzalida, A.; Valdés-Badilla, P. Effects of post-activation potentiation exercises on kicking frequency, fatigue rate and jump performance in taekwondo athletes: A case study. Retos 2020, 68, 679-683. [CrossRef]

27. Da Silva Santos, J.F.; Valenzuela, T.H.; Franchini, E. Can different conditioning activities and rest intervals affect the acute performance of taekwondo turning kick? J. Strength Cond. Res. 2015, 29, 1640-1647. [CrossRef]

28. Chen, H.Y.; Chen, Y.C.; Tung, K.; Chao, H.H.; Wang, H.S. Effects of caffeine and sex on muscle performance and delayed-onset muscle soreness after exercise-induced muscle damage: A double-blind randomized trial. J. Appl. Physiol. 2019, 127, 798-805. [CrossRef]

29. Jacobson, B.H.; Hester, G.M.; Palmer, T.B.; Williams, K.; Pope, Z.K.; Sellers, J.H.; Conchola, E.C.; Woolsey, C.; Estrada, C. Effect of Energy Drink Consumption on Power and Velocity of Selected Sport Performance Activities. J. Strength Cond. Res. 2018, 32, 1613-1618. [CrossRef]

30. Adan, A.; Prat, G.; Fabbri, M.; Sanchez-Turet, M. Early effects of caffeinated and decaffeinated coffee on subjective state and gender differences. Prog. Neuropsychopharmacol. Biol. Psychiatry 2008, 32, 1698-1703. [CrossRef]

31. Rixon, K.P.; Lamont, H.S.; Bemben, M.G. Influence of type of muscle contraction, gender, and lifting experience on postactivation potentiation performance. J. Strength Cond. Res. 2007, 21, 500-505. [CrossRef]

32. Thibault, V.; Guillaume, M.; Berthelot, G.; El Helou, N.; Schaal, K.; Quinquis, L.; Nassif, H.; Tafflet, M.; Escolano, S.; Hermine, O. Women and men in sport performance: The gender gap has not evolved since 1983. J. Sports Sci. Med. 2010, 9, 214. [PubMed]

33. Dos Santos Andrade, M.; Mascarin, N.C.; Foster, R.; de Jármy di Bella, Z.I.; Vancini, R.L.; Barbosa de Lira, C.A. Is muscular strength balance influenced by menstrual cycle in female soccer players? J. Sports Med. Phys. Fit. 2017, 57, 859-864. [CrossRef] [PubMed]

34. Dominguez, R.; Veiga-Herreros, P.; Sanchez-Oliver, A.J.; Montoya, J.J.; Ramos-Alvarez, J.J.; Miguel-Tobal, F.; Lago-Rodriguez, A.; Jodra, P. Acute Effects of Caffeine Intake on Psychological Responses and High-Intensity Exercise Performance. Int. J. Environ. Res. Public Health 2021, 18, 584. [CrossRef] [PubMed]

35. Jodra, P.; Lago-Rodriguez, A.; Sanchez-Oliver, A.J.; Lopez-Samanes, A.; Perez-Lopez, A.; Veiga-Herreros, P.; San Juan, A.F.; Dominguez, R. Effects of caffeine supplementation on physical performance and mood dimensions in elite and trained-recreational athletes. J. Int. Soc. Sports Nutr. 2020, 17, 2. [CrossRef]

36. Ali, A.; O'Donnell, J.; Von Hurst, P.; Foskett, A.; Holland, S.; Starck, C.; Rutherfurd-Markwick, K. Caffeine ingestion enhances perceptual responses during intermittent exercise in female team-game players. J. Sports Sci. 2016, 34, 330-341. [CrossRef] [PubMed]

37. Filip, A.; Wilk, M.; Krzysztofik, M.; Del Coso, J. Inconsistency in the Ergogenic Effect of Caffeine in Athletes Who Regularly Consume Caffeine: Is It Due to the Disparity in the Criteria That Defines Habitual Caffeine Intake? Nutrients 2020, $12,1087$. [CrossRef] 
38. Hsu, G.C. Different glucose levels produced by coffee and decaffeinated coffee using GH-Method: Math-physical medicine (No. 277). J. Diabetes Res. Rev. Rep. 2021, SRC/JDRR-133, 3. [CrossRef]

39. Diaz-Lara, F.J.; Del Coso, J.; Portillo, J.; Areces, F.; García, J.M.; Abián-Vicén, J. Enhancement of High-Intensity Actions and Physical Performance During a Simulated Brazilian Jiu-Jitsu Competition with a Moderate Dose of Caffeine. Int. J. Sports Physiol. Perform. 2016, 11, 861-867. [CrossRef]

40. Wilson, J.M.; Duncan, N.M.; Marin, P.J.; Brown, L.E.; Loenneke, J.P.; Wilson, S.M.; Jo, E.; Lowery, R.P.; Ugrinowitsch, C. Metaanalysis of postactivation potentiation and power: Effects of conditioning activity, volume, gender, rest periods, and training status. J. Strength Cond. Res. 2013, 27, 854-859. [CrossRef]

41. Chtourou, H.; Trabelsi, K.; Ammar, A.; Shephard, R.J.; Bragazzi, N.L. Acute Effects of an "Energy Drink" on Short-Term Maximal Performance, Reaction Times, Psychological and Physiological Parameters: Insights from a Randomized Double-Blind, Placebo-Controlled, Counterbalanced Crossover Trial. Nutrients 2019, 11, 992. [CrossRef] [PubMed]

42. Chaabene, H.; Negra, Y.; Capranica, L.; Bouguezzi, R.; Hachana, Y.; Rouahi, M.A.; Mkaouer, B. Validity and Reliability of a New Test of Planned Agility in Elite Taekwondo Athletes. J. Strength Cond. Res. 2018, 32, 2542-2547. [CrossRef] [PubMed]

43. Da Silva Santos, J.F.; Herrera-Valenzuela, T.; Ribeiro da Mota, G.; Franchini, E. Influence of half-squat intensity and volume on the subsequent countermovement jump and frequency speed of kick test performance in taekwondo athletes. Kinesiology 2016, 48 , 95-102. [CrossRef]

44. Goldstein, A.; Wallace, M.E. Caffeine dependence in schoolchildren? Exp. Clin. Psychopharmacol. 1997, 5, 388-392. [CrossRef] [PubMed]

45. Ryan, R.M.; Frederick, C. On energy, personality, and health: Subjective vitality as a dynamic reflection of well-being. J. Personal 1997, 65, 529-565. [CrossRef]

46. Hardy, C.J.; Rejeski, W.J. Not what, but how one feels: The measurement of affect during exercise. J. Sport Exerc. Psychol. 1989, 11, 304-317. [CrossRef]

47. Foster, C.; Florhaug, J.A.; Franklin, J.; Gottschall, L.; Hrovatin, L.A.; Parker, S.; Doleshal, P.; Dodge, C. A New Approach to Monitoring Exercise Training. J. Strength Cond. Res. 2001, 15, 109-115. [CrossRef]

48. Laurent, C.M.; Green, J.M.; Bishop, P.A.; Sjokvist, J.; Schumacker, R.E.; Richardson, M.T.; Curtner-Smith, M. A practical approach to monitoring recovery: Development of a perceived recovery status scale. J. Strength Cond. Res. 2011, 25, 620-628. [CrossRef]

49. Cohen, J. Statistical Power Analysis for the Behavioural Sciences, 2nd ed.; L Erlbaum Associates: Hillsdale, NJ, USA, 1998.

50. Hopkins, W.G. A scale of magnitudes for effect statistics. New View Stat. 2002, 502, 411.

51. Johnson, M.; Baudin, P.; Ley, A.L.; Collins, D.F. A warm-up routine that incorporates a plyometric protocol potentiates the force-generating capacity of the quadriceps muscles. J. Strength Cond. Res. 2019, 33, 380-389. [CrossRef]

52. Sant'Ana, J.; Franchini, E.; da Silva, V.; Diefenthaeler, F. Effect of fatigue on reaction time, response time, performance time, and kick impact in taekwondo roundhouse kick. Sports Biomech. 2017, 16, 201-209. [CrossRef] [PubMed]

53. Fatouros, I.G.; Jamurtas, A.Z.; Leontsini, D.; Taxildaris, K.; Aggelousis, N.; Kostopoulos, N.; Buckenmeyer, P. Evaluation of plyometric exercise training, weight training, and their combination on vertical jumping performance and leg strength. J. Strength Cond. Res. 2000, 14, 470-476.

54. Yetter, M.; Moir, G.L. The acute effects of heavy back and front squats on speed during forty-meter sprint trials. J. Strength Cond. Res. 2008, 22, 159-165. [CrossRef] [PubMed]

55. Del Coso, J.; Salinero, J.J.; Gonzalez-Millan, C.; Abian-Vicen, J.; Perez-Gonzalez, B. Dose response effects of a caffeine-containing energy drink on muscle performance: A repeated measures design. J. Int. Soc. Sports Nutr. 2012, 9, 21. [CrossRef]

56. Tillin, N.A.; Bishop, D. Factors modulating post-activation potentiation and its effect on performance of subsequent explosive activities. Sports Med. 2009, 39, 147-166. [CrossRef]

57. Maughan, R. Dietary Supplements and the High-Performance Athlete. Int. J. Sport Nutr. Exerc. Metab. 2018, 28, 101. [CrossRef]

58. Arazi, H.; Hoseinihaji, M.; Eghbali, E. The effects of different doses of caffeine on performance, rating of perceived exertion and pain perception in teenagers female karate athletes. Braz. J. Pharm. Sci. 2016, 52, 685-692. [CrossRef]

59. Woolf, K.; Bidwell, W.K.; Carlson, A.G. The Effect of Caffeine as an Ergogenic Aid in Anaerobic Exercise. Int. J. Sport Nutr. Exerc. Metab. 2008, 18, 412-429. [CrossRef]

60. Zhang, B.; Liu, Y.; Wang, X.; Deng, Y.; Zheng, X. Cognition and brain activation in response to various doses of caffeine: A near-infrared spectroscopy study. Front. Psychol. 2020, 11, 1393. [CrossRef] 